\title{
Organization Development Interventions of Asilo de San Vicente de Paul, 2015-2018: A Developmental Study
}

\author{
Sr. Marilou C. Baaco, D.C \\ Ministry with Migrants and Refugees, Daughters of Charity of Saint Vincent de Paul, Province of \\ Saint Louise de Marillac-Asia, Philippines \\ Rosario Cabuhat Alzona, Ph.D. \\ Independent Organization Development (OD) Consultant and Trainer, Philippines
}

\section{Emely Dulig Dicolen}

National Teacher Training Center for the Health Professions, University of the Philippines Manila

\begin{abstract}
This research is a developmental study of the different organization development (OD) interventions undertaken by Asilo de San Vicente de Paul and the documentation of the current stakeholders' experiences. Specifically, it documents and develops a holistic understanding of all the OD interventions undertaken by ASVP from 2015-2018 and recommends further OD intervention plans to be undertaken by the organization from 2019 to 2021 . This is a qualitative research using Appreciative Inquiry (AI) developed by David Cooperrider (1987), utilizing the four cycles of AI, namely: Discovery, Dream, Design, and Destiny as a method in gathering data from the participants through Focus Group Discussions (FGDs) and Key Informant Interviews (KIIs). The results reveal that the OD interventions implemented by the ASVP within the past 3 years were generally beneficial in terms of enriching the spirit of service and volunteerism and in giving focus on the Vincentian values among its stakeholders. However, areas that need improvement are on the following: administration and management, human resource management, and financial management. The results of the research are the basis for the recommendations, specifically, an OD Intervention Plan for ASVP for 2019-2021.
\end{abstract}

Keywords: organization development, social service, appreciative inquiry, organization development intervention, social work/welfare development

\section{INTRODUCTION}

Institutions for social welfare and development services offer vital contributions to society in general. They are usually responsible for helping improve people's lives, including their families and communities through direct care services. These efforts aid people to determine and provide possible interventions on individual and family development.

In response to the emerging global challenges that affect human conditions, a new drive to search for appropriate global solutions had been initiated. With this, the Global Agenda for 
Social Work and Development (2010) was developed as an intervention avenue to help the society to adjust in the further increasing global complexity (Jones, Yuen, et al., 2008 as cited by Jones \& Truell, 2012). The agenda was designed to expand the reach and visibility of social work, to build partnerships and new collaboration opportunities, and to strengthen and lift social workers' confidence to enable them to contribute effectively with developing policies. In theory, the process was an enabling tool to re-position the social work profession on a global scale as social development professionals work side-by-side with policymakers in doing so.

Additionally, the agenda aims to provide sustainable and collaborative outcomes that are based on the skills, experiences, and valuable contributions of the social workers. With their help, solutions can be drawn to tackle global problems that affect both the individual and the society (Sucharipa, 2001; Sweifach, La Porte, et al., 2010 as cited by Jones \& Truell, 2012).

Poverty can be manifested in various forms: physical, mental, psychological, social, moral, spiritual, etc. Social welfare and development services institutions in the Philippines commonly respond to situations of poverty by engaging, assessing, providing interventions, and evaluating individuals, families, groups, organizations, and communities.

\section{Background of the Study}

Asilo de San Vicente de Paul (ASVP) is a social welfare and development institution under the Daughters of Charity (DC) Social Welfare and Development Ministry Cluster. The Institution is registered under the Securities and Exchange Commission (SEC). It is also licensed and accredited by the Department of Social Welfare and Development (DSWD).

For ASVP to continuously respond to serve Jesus Christ in the persons who are living in poverty is a challenge in the revitalization of the mission of transforming the lives of the New Poor. Therefore, ASVP faithfully integrates the Daughters of Charity Provincial Thrust: Alleviation of Extreme Poverty and Hunger, Ministry to Migrants/ Overseas Filipino Workers (OFW's)/Persons Living with human immunodeficiency virus/acquired immunodeficiency syndrome (HIV/AIDS) and their families, and access to primary education and Integrity of Creation in its varied programs and services.

ASVP, once known as Casa de San Vicente de Paul, in our contemporary time, was established on July 26, 1885. It stands as a monument of the living charity of Sr. Asuncion Ventura, DC - its founder who was proclaimed as the first Filipina woman to establish an orphanage in the Philippines. When she obtained her share of inheritance from her family, she legally instituted the transfer of this inheritance to the Daughters of Charity. "The Daughters of Charity, in fidelity to their baptism and response to a divine call, give themselves entirely and in the community to the service of Christ in their brothers and sisters who are poor, in an evangelical spirit of humility, simplicity, and charity. (Company of the Daughters of Charity of St. Vincent de Paul, Constitution and Statutes, c.7a, 2004)

Deep faith and trust in the Divine Providence have sustained the life of ASVP as it has survived 133 years of existence. The Institution started with 33 wards, providing asylum and lodging to the homeless. For ASVP to continuously respond to serve Jesus Christ in the persons who are living in poverty is a challenge in the revitalization of the mission of transforming the lives of the New Poor. Therefore, ASVP faithfully integrates the DC Provincial Thrust: Alleviation of Extreme Poverty and Hunger, Ministry to Migrants/OFWs /Persons Living with HIV/AIDS and their families, and access to primary education and Integrity of Creation in its varied programs and services.

At the start of the 21st century, there was a resounding call for ASVP to open its door to the new faces of the poor. After a period of discernment and reflection processes within the DC 
Philippine Province, ASVP reclaimed its original purpose of existence - to provide safe and peaceful residential care for the children in difficult situations and to facilitate access for the people living in poverty situation as a community-based service to nearby barangays. ASVP being in a strategic location is accessible to varied social service facilities - hospitals, schools, offices, and seafarer companies, etc.

"Saint Vincent emphasizes the radicality of the vocation of the Daughters of Charity: "They will consider that since their ministries oblige them to be out of the house and among the people most of the time, and often even all alone, they need greater perfection than Sisters who minister in hospitals and other similar places, which they rarely leave"' (The Boldness of Charity, Inter Assemblies Document 2015-2021, 2015). Until now they are still being called to live the Gospel in the world in a "radical way," following the example of Saint Vincent and Saint Louise: "the passion for Christ and for persons who are poor."

ASVP, trying to serve as a role model in the social welfare and development field, does not want to work with mediocrity. Rather, a more dynamic approach is needed. Consistent improvement, changes, and development are all underway to serve its clients, donors/benefactors, and partners better, to expand their horizon as they offer unique and more memorable experiences as a Haven of Hope. The Administration believes that not to transform in today's environment will be to die as an organization thereby not being able to serve its mission. Hence, several required organization development interventions were implemented to further sustain the Institution.

\section{Research Significance}

This study was a significant endeavor to provide top management and the whole organization's human resources with knowledge and understanding of the different OD interventions undertaken by ASVP. The results of the research would be of prime significance to all the stakeholders of ASVP. Their knowledge of the OD interventions, their outcomes, and accomplishments, would lead them to an appreciation and ownership of their contributions to the organization, thereby motivating them to perform better. Furthermore, this study would also lead to the future model building on the part of the organization to be able to understand more the cause and effect relationships of the different variables that come to interplay. Future OD practitioners in the Institution may document all the key result areas and key performance indicators that would establish the real conceptual model on the cause and effect relationships that come to play in the implementation of OD interventions in their setting.

To the social welfare and development sector and business practitioners in OD, the study would inform them of the area of OD intervention management, objectives, and strategies. It could also serve as a reference for researchers on the subject of OD and Institutions. Moreover, the findings of this study can inspire and influence other qualitative studies to explore more about the research variables for a further and deeper understanding of the concepts involved.

Furthermore, this research could also become a model for other service institutions who are offering similar services. The results may encourage the administrators of such institutions to undergo similar processes to further improve their programs, maximizing quality service to their clients and stakeholders.

\section{Theoretical and Practical Gap}

Numerous studies on organization development have been published in different settings such as service and manufacturing industries. However, there is a dearth of researches conducted or literature written about OD in social work/welfare and development. Thus, there is no specific theory ever published nor proven that is along this line. 
Furthermore, there is no significant documentation of OD interventions done in the Philippines concerning social work and/or social welfare and development institutions. The scarce literature, both locally and internationally, proves this. Moreover, within the Institution, projects undertaken were not fully documented and not being assessed and evaluated, especially when it comes to the factors that affect their implementation on the Clients, as well as other stakeholders of the Institution. Questions on the goals and objectives expected to be attained by certain intervention programs in the past, which focused more on seminars, as well as their effects specifically on the clients are left unanswered. Hence, there was no assessment of the impact and whether these interventions need to be stopped or continued. These assessment and evaluation might have been the basis of plans for the Institution to become better and better and hence, really attain its excellence.

This study, specifically with the ASVP, attempts to bridge the abovementioned theoretical and literature gaps. Concretely, this shall become a model study that can be replicated in other social work/welfare institutions with similar nature.

\section{Research Objectives and Problem Statement}

The main purpose of this research study was to undertake a developmental study on the different organization development (OD) interventions done by ASVP from the year 2015 to 2018. Specifically, the study aimed to carry out the following with its relevant stakeholders: 1) Document the OD interventions undertaken by ASVP from 2015 to 2018; 2) Develop a holistic understanding of all OD interventions that are undertaken by ASVP from 2015 to 2018; 3) Document all immediate outcomes and accomplishments of ASVP from 2015 to 2018; and, 4) Recommend an OD Intervention Action Plan for 2019 to 2021.

The study aimed to answer the following questions: 1) What are the organization development (OD) interventions undertaken from 2015 to 2018?; 2) What are the goals and objectives, activities, entities, processes and forces, and contexts that influenced, enabled, or constrained the implementation of OD interventions?; 3) What are the immediate results and outcomes experienced by ASVP in its operations in 2018?; and 4) What are the recommended OD Action Plans to be undertaken by the organization from 2019 to 2021?

\section{LITERATURE REVIEW}

Literature and studies on concepts and theories that are relevant to the development of this study were reviewed to draw an overall guide and foundation for the structure of the research. Topics reviewed include theories and models of organization development (OD) and OD interventions, research and applications of Appreciative Inquiry (AI), Balanced Scorecard (BSC), organizational change, moments of truth and learning organization.

\section{Organization Development}

Through the years, the range of the definition for OD had expanded continuously. Although a lot of definitions have surfaced, the concept of change will always be constant in these. Change, may it be planned or not, is always associated when it comes to people's perception of OD. Cummings and Worley (as cited by McLean, 2005) proposed the definition of OD as "a system-wide application and transfer of behavioral science knowledge" to formulate different reinforcements and intervention processes that will eventually lead to increased effectiveness of the organization.

The field of OD had been explored as a significant factor for constructive change at the societal level (Brown, Leach, \& Covey, 2008). In their study, they explored how OD tools and strategies can help in strategic and overall impacts to the organization. The study indicated the implications of OD and its tools for interventions, as well as the aid of practitioners in the field and to society. 


\section{Organization Development Interventions}

For an intervention to be effective, the intervention design should be able to consider the situational contingencies and customize the design to the needs of the whole organization. The following are the types of organization interventions according to Cummings \& Worley (2009):

1. Strategic Interventions - establish the relationship between the vision, mission, values, plans, the internal functioning of the organization, and its ever-changing larger environment. These interventions originated from the disciplines of strategic management and other organization theories that link the business strategy, organizational culture, and structure to its larger environment.

2. Technostructural Interventions - are methods that focus on employee involvement concerning productivity and organizational effectiveness. It stresses that effective work designs and structures are only met when the human capital is fulfilled and productive in their respective roles inside the organization. These interventions generally focus on structural design, downsizing, and re-engineering.

3. Human Process Interventions - focus on the achievement of organizational effectiveness through the improved functioning of human capital and processes inside the organization. It considers the processes of communication, decision making, and leadership.

4. Human Resources Management Interventions - focus on people management within the organization including recruitment, personnel management, performance appraisal, reward systems, and the provision of direction/ladder of the employees within the organization. These interventions typically concentrate on enhancing human capital management to achieve organizational effectiveness.

According to Resnick and Menefee (1993), one of the concrete innovations in social work and development practice is the inclusion of organization development technologies to strengthen the capacity of social work practitioners in effecting organizational changes responsive to the changing social conditions.

\section{Appreciative Inquiry}

One emerging approach to OD is the Appreciative Inquiry (AI) process. AI starts from the perspective that the organization is already doing many things well, that members are aware of these successes, and that a process for building and sharing institutional/organizational successes is critical to engaging the entire organization in planning for the future. The planning framework can help in shaping the vision of the organization in the demanding and rapidly changing environment of the 21 st century.

AI is a challenge to the traditional methods of providing leadership and planning for and managing change. However, Gomez, Bracho, and Hernandez (2014) reiterated the importance of AI in social work development institutions as a tool in changing the stakeholders' perceptions leading to the empowerment of the administrators, staff, clients, and partners of the organization.

$\mathrm{AI}$ is based on the following beliefs:

- Organizations are not like machines - they do not have an objective reality the way a material thing does.

- Organizations are a social reality and they are co-constructed; that is, through people's interaction with each other. 
- Important human processes like communication, decision-making, and conflict management are affected by how the people involved making meaning out of their interactions than by the skillful application of any technique.

- Attempts to find or develop the right formula for successful leadership and change are misguided; we cannot treat social reality as if it were objective reality.

The pioneers in the field of study for AI had great contributions to the evolution of its practice. The general outline or illustration of the phases of AI can be explored by the 4D model. The 4D model is comprised of 1) discovery, 2) dream, 3) design, and 4) delivery or destiny.

1. Discovery - this is the phase of the continuous search and identification of how something comes to life. Bushe (2011) describes it as the stage of discussing "what" is concerning the subject or object of the inquiry. It is what they call the moment of identifying the "best of what is" (Ludema, as cited by Moore, 2020).

2. Dream - the stage of imagining potentials. This phase is usually the most symbolic, as the aspirations, plans, and visions are being conceptualized (Bushe, 2011).

3. Design - Cooperrider (1987) described this phase as the "key" for a sustainable positive change. This is where the co-construction and dialogue usually take place to strengthen the plans and make it much achievable.

4. Delivery or Destiny - the purpose of the last phase is to construct and co-create futures "through innovation and action" (Ludema, as cited by Moore, 2020). It was originally called the delivery stage but was later on replaced as it provokes the traditional implementation of change management (Bushe, 2011).

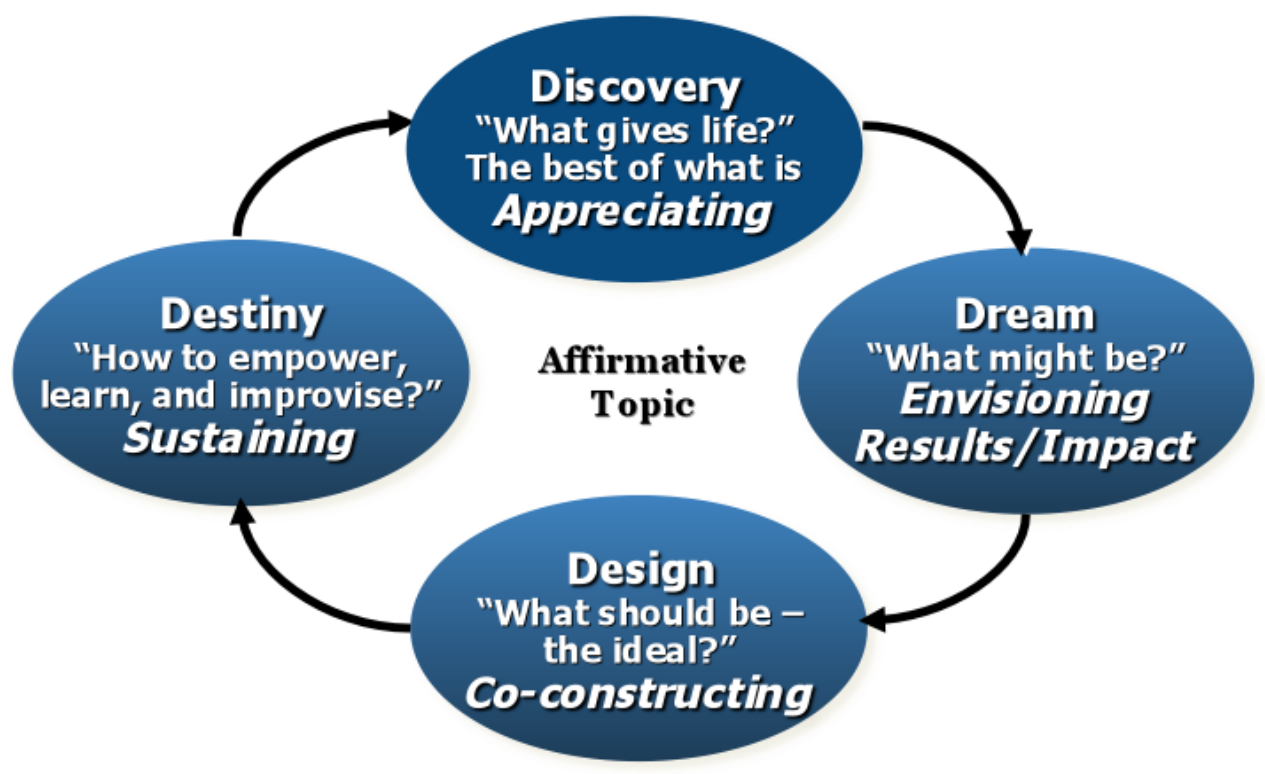

Figure 1. 4D Model of Appreciate Inquiry (Cooperrider \& Godwin, 2012, p. 39)

In the implementation of AI as an approach in changing the landscape of social work development institutions, leadership and supervision are very crucial because the leaders' role is not only focused on problem-solving. Cojocaru (2010) encourages the use of appreciative supervision to bring about thoughtful changes in the organization, which the ASVP administration aspires to achieve. 
Most often, AI applications in organizations involve the change in the manner of language and attitude (Gomez et al., 2014). Social workers, as enablers of empowerment in communities, functions through disseminating information on community member's rights and obligations to the society and the nation. To this profession, AI application is a manner of transformation. Gomez et al. (2014) view their importance as therapists by communicating and interacting with the citizen, so their manner of communication and attitude is as important as their role in society.

Paddock (2003) stated what Rick Krivanka, a staff member of the Pastoral Planning Office at the Diocese of Cleveland, believed that when one begins the Appreciative Inquiry process, one creates a change in the culture within the organization to become more life-centered.

\section{Balanced Scorecard (BSC) Method}

Performance measurement processes are important in every institution or organization. Since the emergence of the importance of studies that explore the measurement of company performance, traditional ways of performance evaluation in financial performance measurement was no longer seen as an effective indicator of success in the modern economy (Isoraite, 2008). As a result, studies explored different ways on how to record organizational activities in a more holistic assessment through the approach of Balanced Scorecards (BSC).

BSC is a management system that can be defined as the translation of organizational strategies into specific actions (Kaplan \& Norton, as cited by Isoraite, 2008). Through this method, an organization can combine traditional strategies and formulate new ones that fit the demands of their stakeholders. The Balanced Scorecard Institute (n.d.) views BSC as a holistic approach that fills the gap of current strategies by introducing new ones that will result in a more balanced view of performance. Proper execution of the BSC method should provide "visible connections" to the organization's activities, strategies, and further plans of action.

Isoraite (2008) included in the research that BSC is a "unilateral measurement" that assesses a certain organization's ability to perform. The BSC organized in the research conducted had four perspectives, namely: the financial, the customer, the internal, and the learning perspective.

Another study conducted by Georgiev (2017) explored the role of BSC as an essential element of strategic management and control. The study concluded that the intangible capital such as human, social, and emotional investments of an organization and its members are far more essential than any the physical capital they have. Most often, the physical capital is given more importance, but according to this research, a balanced method of managing and handling all resources - tangible or not, will lead to the overall sustainable growth of the organization.

\section{Organizational Change}

Leadership is nothing if not about change (Clawson, 2003). Effective leaders are masters of the change process: they understand, embrace, and lead change. Clawson also cites that:

"leading changes is like dropping a pebble in the pond: there is an initial splash, and then, if it

is to be successful, concentric waves emanate out from the center. The leader with the vision is that

center, and the team he has assembled becomes the waves that affect the rest of the pond spreading its word."

(Clawson, 2008, p. 7)

A leader cannot initiate change by himself because the process involves letting go of one part and the birth of a new one.

Fox (2013) describes the environment of non-profit and social work organizations as chaotic due to the existing threats to the organization itself, its values, and its clients. These are changing political conditions, competing human services organizations, increased demand for services, and decreasing resources (Steiner, Gross, Ruffolo, \& Murray as cited by Fox, 2013). 
Organizational change is imperative to improve the performance of both the for-profit and non-profit organizations to improve its performance in solving problems and in fostering change at the societal level (Brown et al., 2008).

Thus, organizational change is imperative in all social work development institutions such as the ASVP.

\section{Moments of Truth}

An organization does not only interact within and among employees and members. Most organizations function to provide customer or client services. Service research had been evolving as a multidisciplinary field with explorations on the matters of antecedents, involved processes, and the effects or outcomes of the relationship between the client and the organization in a customer service setting (Goth, Wu, Nguyen, \& Johnson, 2019).

Goth et al. (2019) explored the different aspects that concern interpersonal service, which is the interaction that happens between the employees or members and the customers or clients. They focused on the 1) affect in the customer service setting such as emotional labor and the processes involved in emotional contagion; 2) customer mistreatment situations such as lowquality of customer or client treatment; 3 ) the behaviors in a customer service setting like customer orientation and service behaviors towards citizenship. In this case, the study helped in providing implications for further research and studies in the service context. It also supplied applications that might be useful for the managers of the organization or the service institution.

Additionally, in the business and service context, the terminology "Moment of Truth" (MOT) is often discussed. This term is often explored as the most significant "touchpoint" or customer interactions. According to Smith (2017), MOT can begin in two situations: a) once the client or customer decides to accept the organization or business proposal, and b) by the end of the transaction as they provide good or bad feedback for the service.

In the research of MOT, Normann is often cited as the pioneer researcher in the field who provided important points in studying MOT. He said that the customer is not just a customer; the customer is way more than what they are. According to him, he or she plays a vital role in the organization or the business as he or she is also a participant of the service (Normann, as cited by Smith, 2017). He insisted customers and clients are important in the process of value creation. Cocreation, as he described it, happens when the external forces and the internal forces collaborated for a desired output or value. In the service context, when the customer or client is not involved, the value cannot be created as it is a product between them and the organization.

\section{Learning Organization}

During the evolution of the different organizations, institutions, and consultation services, a lot of them realized the importance of organizational learning. With this, associating the term "learning organization" as a central perspective had been very helpful. Learning organizations can be defined in many ways. However, most definitions are rooted in Senge's definition. He described it as an organization where there are continuous search and exploration of each member's or employee's capacity to learn and achieve their goals or desired results (Senge, as cited by Hussein, Mohamad, Noordin, \& Ishak, 2014).

In an attempt to explore Senge's definition, some of the studies explored the effect of learning in organizations as an initiator of innovation. As such, Senge's concept of a learning organization as the facilitator or enabler of responsible innovation. Responsible innovation is often related to competitive advantage as most innovations tend to achieve an increase in business or organizational competency. Due to these associations, a close relationship between the status of a 
learning organization and the positive organizational outcomes are being drawn. In some cases, positive effects on the organization's ethics and morale is often a result of a high learning organization status (Hansen, Jensen, \& Nguyen, 2020).

\section{Research Framework}

This study looked at all the OD interventions undertaken from 2015 to 2018 at ASVP. It emphasized on the tools and methodologies used, as well as the objectives expected to be attained by the said interventions.

As shown in Figure 2, the AI process was undertaken on ASVP in May 2015 as developed into phases with the following defined outcomes:

1. Life-giving forces: Identified energizing forces

2. Propositions for the Future: Strategic Goals

3. Design and Plans for the next three years, 2016-2019.

Paradigm Change from the traditional planning method to the positive affirmation or AI within ASVP is expected as the outcome of the study. The timeline of positive milestones was established for the next three years.

Based on the core factors (life-giving forces) identified, provocative propositions for the next three years were formulated giving rise to ASVP's vision, mission, and values. The said vision, mission, and values were thus communicated to all stakeholders as the basis for the formulation of strategic goals which were later translated to action plans - specific programs and projects using the Balanced Scorecard for organizational transformation.

Several interventions were undertaken as part of the programs and projects. These were strategic interventions (establishing desired culture and change), techno-structural interventions (restructuring, systems and procedures development and enhancement), human process interventions (Human Relations programs), and human relations management intervention (learning and development projects).

By the middle of 2018, several outcomes were observed. As discussed in the study's limitations, the analysis of financial results was not done. The key performance indicators are not completed yet by the respective departments and units hence, no causal relationship could be established.

\section{RESEARCH METHODOLOGY}

The following provides a discussion on the research design and strategy and data collection and analysis used in this study.

\section{Research Design}

The study involved developmental action research which involved a qualitative description of the various OD interventions undertaken for ASVP from 2015 to 2018, including the methods and tools used in all these interventions. This type of study allowed secondary data collection, observation, and interviews without affecting the normal behavior of the organization.

In qualitative research, the researchers attempt to analyze the scenarios in much broader terms than quantitative research would (Neuman, 2011). It was used for Focus Group Discussions (FGDs) and Key Informant Interviews (KIIs). 


\section{Research Strategy}

The study was conducted at ASVP with a total of 39 employees, 81 resident clients, and 17 extern clients. Purposive and convenient sampling designs were used to identify the participants for the study. Using convenience sampling, respondents from within the Institution were stratified by departments. "Convenience sampling is also known as grab, opportunity, accidental or haphazard sampling that are easy to reach" (Kahl, 2020). As such, convenience sampling is a non-probability method since subjects are chosen in a non-random manner and some members of the population have no chance of being included.

The advantages of this type of sampling are the availability and the quickness with which data can be gathered particularly when time is a constraint. The majority of the research population opt for this sampling method since they can easily collect data to begin their analysis faster.

The participants of the FGDs were the Unit Heads of the different departments, namely: Administrative Services \& Finance Department (ASFD), Pastoral Care Services Department (PCSD), and Social Welfare \& Development Department (SWDD). The resident/client participants were from the Blessed Rosalie Rendu Home (Rendu), San Pedro Calungsod Home (SPC), Elizabeth Seton Home (Seton), Sister Asuncion Ventura Educational Ultimate Service (SAVE-US), Technical Vocational Education and Training (TVET) Program; and People on the Move. Specifically, among the 39 employees, $28 \%$ were chosen and among the 81 resident clients, $34.5 \%$ were part of the FGDs.

The KIIs were conducted to further validate or verify the results of the FGDs. The sample consisted of five (5) major donors and benefactors. All five (5) members of the Administrative Council were included as they are critical to enhancing the validity of the conclusions drawn. Table 1 shows the number of samples for the FGDs and the KIIs.

\section{Table 1. FGD and KII participant's distribution.}

\begin{tabular}{|c|c|c|c|c|c|c|}
\hline \multicolumn{4}{|c|}{ Focus Group Discussion } & \multicolumn{2}{|c|}{$\begin{array}{l}\text { Key Informant } \\
\text { Interviews }\end{array}$} & \multirow[b]{2}{*}{ GRAND TOTAL } \\
\hline $\begin{array}{l}\text { Lay Mission } \\
\text { Partners }\end{array}$ & $\begin{array}{c}\text { \# of } \\
\text { participants }\end{array}$ & Residents & $\begin{array}{c}\text { \# of } \\
\text { participants }\end{array}$ & Admin Council & $\begin{array}{l}\text { Sponsors/ } \\
\text { Benefactors }\end{array}$ & \\
\hline SWDD & 5 & Rendu & 5 & 5 & 5 & \\
\hline PCSD & 3 & SPC & 5 & & & \\
\hline \multirow[t]{5}{*}{ ASFD } & 4 & Seton & 4 & & & \\
\hline & & TVET & 2 & & & \\
\hline & & SAVE US-A & 4 & & & \\
\hline & & SAVE US-C & 3 & & & \\
\hline & & $\begin{array}{l}\text { People on } \\
\text { the Move }\end{array}$ & 5 & & & \\
\hline Sub Total & 12 & & 28 & 5 & 5 & \\
\hline $\begin{array}{l}\text { GRAND } \\
\text { TOTAL }\end{array}$ & & 40 & & & & 50 \\
\hline
\end{tabular}

The guide questions for the conduct of the FGDs and KIIs were developed (see Annexure 1 and 2). To ensure the effectiveness of data collection, pretesting of instruments was done to conform to the requirements of validity, reliability, and practicality.

Validity is the extent to which a test measures what it intends to measure. Reliability is concerned with both accuracy and precision. While practicality is more likely associated with the different factors of the economy. It is also influenced by the levels of convenience, as well as the interpretability of results (Thorndike \& Hagen, 1969).

Reliability has to do with the accuracy and precision of a measurement procedure. Practicality, on the other hand, is concerned with a wide range of factors of economy, convenience, and interpretability (Thorndike and Hagen, 1969). 
Most researches refer to Willis (2007) three-factor when they evaluate the scientific contribution of their qualitative studies. These factors are 1) coherence - this factor looks into whether the study makes sense with the data and variables involved; 2) consensus - this is the overall agreement of the soundness of the study; and 3) instrumental utility - this investigates whether the study is replicable and if it can be applied.

The tools were pre-tested specifically with those who were not part of the study samples. Feedback from the sampled respondents during the pre-testing indicated that all questions in the FGD and KII tools were clear. This confirmed the practicality and replicability of the instruments. The instruments were then presented to the Administrative Council for approval.

\section{Data Collection and Analysis}

The research had undertaken several processes in collecting and gathering data for analysis. First, an exhaustive analysis of secondary literature and studies pertinent to the current study, specifically, available literature related to OD, management, and AI. Second, available records of ASVP were also studied to give meaning to the OD interventions undertaken in the Institution. Third, focus group discussions (FGDs) were done among selected participants. Lastly, Key Informant Interviews (KIIs) were administered to key officials, particularly, administrators and units-incharge in the organization. The FGDs and KIIs were conducted to obtain data from the participants. The results were processed using Appreciative Inquiry as a research methodology following the 4D cycle, that is, discover, dream, design, and destiny.

The secondary data available at the ASVP such as manuals, handbooks, reports, documentation of procedures, systems and processes, and training evaluation documents were used. Likewise, readings and articles about OD and AI were utilized. The questions for the FGDs and KIIs were focused on the participants' involvement in various ASVP programs, services, and activities; their most significant/memorable experiences while at ASVP; and their wishes/vision for themselves and ASVP.

The confidentiality of information provided by respondents was strictly followed. This gave them more encouragement to express the effect and impact of the OD interventions on them and the organization. The data gathered from the FGDs were recorded with the permission of the participants. The proceedings were then transcribed verbatim to capture the necessary details from the FGD. The transcribed data were then thematically coded and analyzed. The identified themes were discussed lengthily and corroborated with literature cited in the study and were also deepened by significant statements from the participants themselves. As such, these themes were also validated by the results of the KIIs from the key managers and administrators of ASVP. The data were further grounded in the literature from experts and secondary data available at ASVP.

It is seen that triangulation was used. The main objective of triangulation is to provide objective evidence/proof of the responses given by using a variety of data gathering tools: documents, observations, FGDs, and KIIs. Triangulation was used to integrate all the results that were gathered. The results processed from secondary data were used as the basis for the FGD. Moreover, KII was utilized to confirm the results from the documents and the FGDs.

\section{FINDINGS AND DATA ANALYSIS}

The discussion of the findings proceeds according to the order of the research questions.

Based on several meetings and discussions with top management, ASVP is PASSIONATELY learning from the PAST, focusing on the PRESENT, and creating the future, through meaningful relationships, living life to the FULLEST. 


\section{The OD Interventions of ASVP from 2015-2018 and Their Immediate Outcomes}

The OD interventions undertaken by ASVP from 2015-2018 were the following: strategic interventions, techno-structural interventions, human process interventions, and human resource management interventions. These are illustrated in Figure 2.

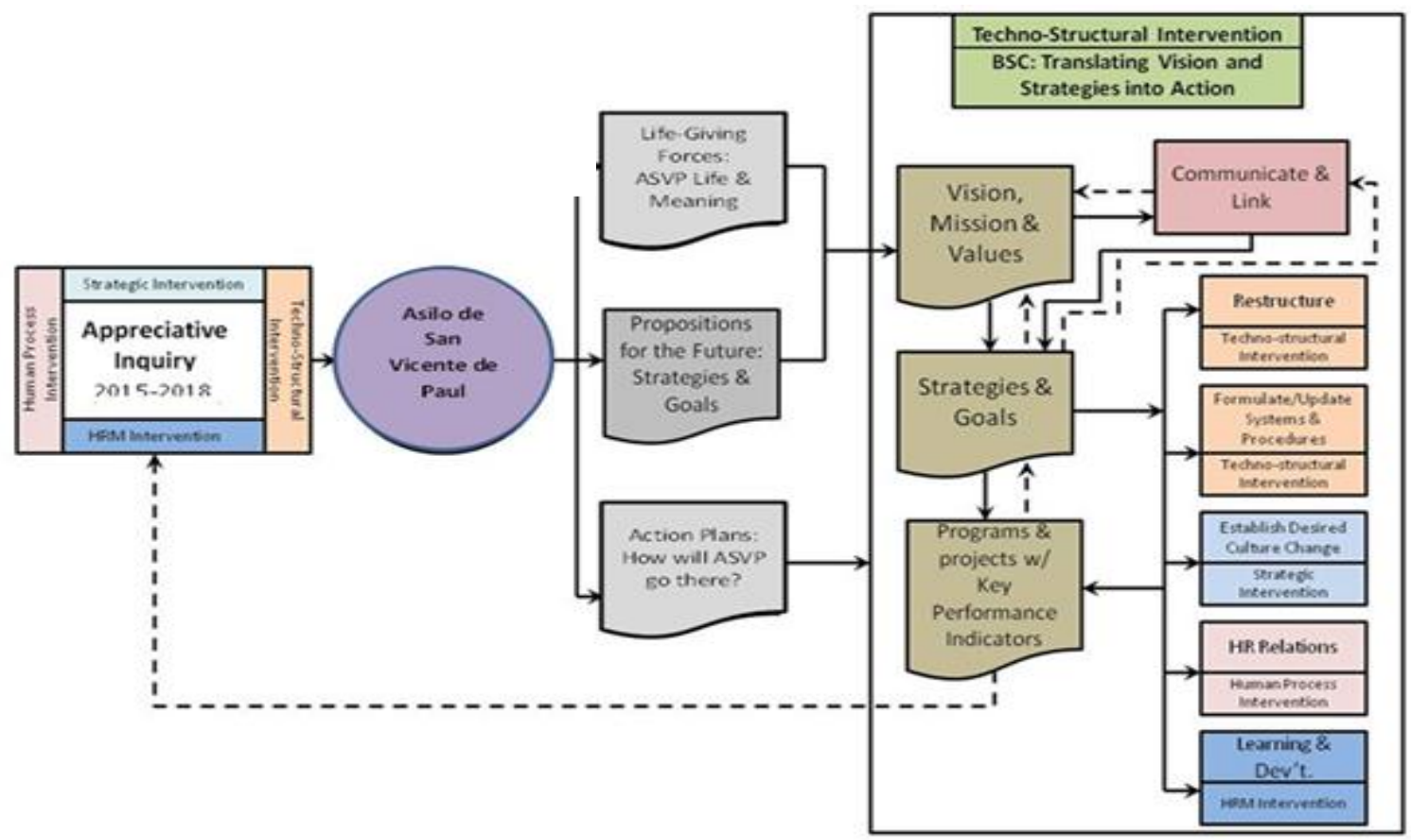

Figure 2. The Organization Development Interventions of ASVP from 2015-2018

The following are the immediate outcomes of the abovementioned interventions as articulated by the research participants of the FGDs and KIIs.

\section{A. The Lay Mission Partners (LaMPs)}

1. The strategic interventions helped them gain a better understanding of their current state and environment allowing everyone to better target strategies for collaborating with clients, donors/benefactors, individual partners, and partner organizations. The first AI workshops done in 2013 led to the realization of the best experiences they had within the Institution including the attainment of the DSWD Level 2 accreditation in implementing residential-based programs and services for children and youth. This accomplishment shows that AI contributed significantly to the positive revolution that has helped transform ASVP as an organization and as a community (Bushe \& Marshak, 2009).

One participant declared:

When we were able to concretize the vision, mission, and values, we were so happy. We started being a community of people appreciating each other. Until now, I am trying to apply it. I'm trying to look at the positive side of life - starting and ending the day with a positive disposition in my life.

The overall feedback on the use of AI as an OD intervention at ASVP is a philosophy grounded in dialogue and reflection-based practices that can stimulate organizational innovation orchestrated through shared leadership principles. With the application of the intervention, as well as related AI principles, there would be an advancement in terms of individual leadership skills and enhancement on the organization's capability to learn under certain circumstances. As such, the constant processes of reflecting, reframing, and reinterpreting lessons and learnings can be a 
continuous inquiry on how to appreciate, how to apply them in real-life situations, how to be provocative, and how to interact and collaborate with others (Somerville \& Farner, 2012).

Likewise, participants unanimously agreed that the development of the BSC was beneficial to all the stakeholders of ASVP. One participant also said:
$B S C$ is perfect. We were able to identify our specific roles. These became clearer when they were related to the Moments of Truth. Expectations became clearer in our department. The different departments became more systematic. I certainly appreciated it because the delivery of services became more systematic.

It was further observed that all the seminars facilitated not only focused on the technical competence of the people; but also allowed them to boost their morale, build self-confidence, and articulate their minds and feelings. As a result, they were able to create an environment that can be categorized as a learning organization. Senge (as cited by Hansen et al., 2019) defined learning organization as an avenue "where new and expansive patterns of thinking are nurtured, where collective aspiration is set free, and where people are continually learning how to learn together."

2. The techno-structural interventions assisted in improving organizational effectiveness and human development as they focused on organizational restructuring, job analysis, and business process redesigning.

"The Moments of Truth are an answer to my prayer," one of the participants exclaimed because it means a clearer definition of roles and functions. The staff realized that now, they "do not have to leave their main roles as case managers due to intervening works." Through the Moments of Truth, it is assured that "there's no task left behind." The participants agreed that these steps and procedures depict the roles, tasks, and responsibilities of each employee in ASVP. They all acceded that these must be in place so that whoever takes over their positions or will be handling their tasks would not be left groping in the dark because the standards have been firmed up. "Even other people will be assigned to do the same task, they will not be lost because they will be following the same system", one of the FGD participants added.

For one participant, she realized that the "Moments of Truth" are directing and guiding her as she performs her role as a social worker. She realized that the extent of her role and the way she handles the cases will be reflected in the results.

Another participant said, "Moments of Truth was very belpful because the schedules of the staff were put in order." Moreover, one of the staff commented that a copy of the Moments of Truth sessions must be submitted to the Human Resource Office so that it can be included in the orientation of new employees concerning his/her roles and responsibilities. This would further help the applicant adapt as he/she assumes his/her role in the Institution.

3. The human process interventions helped the ASVP to focus on their people, as well as the processes that they need to complete to accomplish their organization's goals. These include communication, problem-solving, group decision making, and leadership.

$\mathrm{AI}$ as a paradigm shift was introduced to open the mind and spirits of people specifically the Institution's leaders. The following projects were undertaken:

a. Seminar-Workshop on Leadership: Creating Alignment of Strengths Towards Employee Engagement. An engagement survey was conducted during the workshop and one participant affirmed, "All the employees are engaged, totally engaged. Although there are employees who are partially engaged, maybe this is due to some personal reasons."

The participants agreed that the seminar had a positive impact on themselves personally and to the whole institution. Furthermore, they learned deeply about work engagement, and they are very 
committed to staying fully engaged in their work. In a paper presented by Raziq and Maulabakhsh (2015), they found out that a good employee-employer relationship provides a higher job satisfaction rate for the employees. As such, the relationships they have with their co-workers were essential in establishing a positive overall feedback to their organization and their tasks or jobs.

They also learned to approach the people in the organization with gentleness. One participant said: "I learned how to approach people. Sometimes, I am impatient. Now, I learned how to be firm but gentle to all the staff in my organization." In simpler terms, a positive social work approach gives great importance to a good client and worker relationship (Kreiviniene \& Rimkus, 2016).

The participants further learned that affirmation is important in keeping their relationships in the organization and that focusing on the negative attitudes of their co-workers is not healthy. One of the participants narrated: "I should be positive. I should point out the positive in a person." Somebody added: "And we should learn how to affirm especially when somebody has done something good!" This remark affirms what Fredrickson (2001) wrote in an article that positive emotions are signifiers of a flourishing, healthy, and optimal overall well-being.

b. Seminar-Workshop on Appreciative Coaching. Appreciative coaching is a relational process in which the coach leads by shining the light on the person coached. During the said workshop, the emotional intelligence (EI) of all participants was explored using the emotional quotient (EQ) map. Most of the participants learned how to further motivate their staff through coaching. Several findings cited the importance of EI to an individual's strengths and weaknesses, work performance, collaboration satisfaction, and most importantly, reflecting and interpreting an individual's emotions and feelings (Relojo, et al. as cited by Sfetcu, 2020).

c. One-on-One Individual Coaching. Through this process, the OD Consultant believed that the leaders would be prepared to mentor and coach their subordinates toward their further development and the achievement of corporate goals and objectives. Hashmi (2018) posits that the commitment of the management team is crucial for organizational change to occur and that mentoring one-on-one should be done in the whole organization.

The participants felt their value and importance as they went through coaching. They just hope that the administration/top management would help them continue this activity. They added that they should also do coaching for their immediate subordinates.

4. The human resource management interventions helped them come up with and institutionalize the Performance Management System and the Planning, Monitoring, and Evaluation System.

Generally, the LaMPs agreed that all interventions introduced to the Institution for its development are beneficial. It can be summed up with the following quotes from the LaMPs, "I am happy with all the seminars/workshops. I don't feel stagnant. Everything taught to us is important. We appreciate new learnings. Gradually we will be able to live out everything that we have learned."

\section{B. The Residents}

The following are the results of interviews with the different groups of residents about the best experiences they have had while under the care of ASVP:

1. Basic Needs (Food, Clothing, and Shelter)

The residents were unanimous in identifying the provision of their basic needs such as food, clothing, and shelter as the most significant service that they have been receiving since they arrived at ASVP. According to them, the food served is of proper nutrition and is enough for everyone. Somebody noted, "I am happy with the food they are giving me." One even gratefully mentioned that they do not have to worry about their next meal because everything is provided to them unlike when they used to live with their families on the streets. 
Regarding clothing, the residents were grateful that they have decent clothes to wear. They were also very thankful to the donors who come and give them clothes. Like food, they no longer need to worry about what they would wear since it is also provided to them by the Institution.

"The homeless can live here," exclaimed one of the boys. He added, "I'm bappy here because unlike when I was living with my mother, I couldn't sleep because it's hot. Now, I'm more comfortable." The children appreciated the comfort they are experiencing at the Institution because they have a home where they can sleep. Also, they have nothing to worry about when it rains, when a typhoon strikes, or even when the summer season comes. They are all sheltered and well taken care of.

One SAVE-US resident also shared, 'T'm so grateful because the lodging fee is so affordable. This is a big help to us scholars whose budget is limited."

2. Educational Assistance

All the children including those of the refugees are sent to good schools near ASVP. Through the help of the sisters and benefactors, they have access to quality education and learning materials such as textbooks and school supplies. They even have access to computers and other resources in the facility. Aside from this, they are also offered free tutorials by the Institution's volunteers.

The residents knew that the education given to them is an important tool for their better future. One child said, "My education is a tool for me to get a good job and to have a brighter future." The children acknowledged that education can "strengthen their morality" and will help them in making decisions for themselves in the future. A SAVE-US resident shared, "this is a big help to us and to our parents. It is difficult and it entails plenty of sacrifices, but I am surviving. I just need to motivate myself. I learned this while in Asilo (ASVP)."

For Pakistani families, there is a big opportunity for parents to send their children to private quality institutions, with scholarships provided by the partner schools and universities. Aside from the free tuition fees, they are also provided with all the supplies, textbooks, reference materials, and computers that they need to be able to pass all their subjects. One parent expressed, "T am very happy that my children are also provided tutors to help them in their homework which I cannot perform to my children because of some language barriers."

3. Safety and Security

"T'm happy because there's no chaos here unlike when I was still living at Pandacan," shared by one of the boys. He appreciated the fact that at ASVP, he did not have to worry that something wrong might happen to him. He was sure that he could sleep tight and peacefully during the night. He added, "here, I have peace of mind that nothing wrong will happen to me."

The children's concept of inclusivity and openness to other cultures was very admirable. They were not only concerned about their safety as Filipino children but also for other children as well, regardless of their nationality. One remarked, "we are sure of our safety here, regardless of race. Asilo (ASVP) does not choose whom to belp."

\section{Faith/Spiritual/Values Formation}

The residents appreciated their frequent participation in the Holy Mass and other religious activities because they get to deepen their relationship with God. As they perform active roles as choir members and altar servers, they get to discover their potentials in music, particularly in singing and playing musical instruments such as the banduria. One boy testified, "I am not used to praying before I came to ASVP. I did not also attend masses. But then I came to this institution, I got the chance to go to mass every day and I became an altar server. Now, I go to mass daily and I learned how to pray."

As Reed (2014) describes, the study of AI will never be judgmental. Since its emphasis is entirely on the process of appreciation, it becomes a perspective with no dependence on the idea 
of what is right and what is wrong, but simply on what is presently happening. The idea of spirituality coexists in the same nature.

The most favored activity which the residents enjoyed was the outreach initiatives that ASVP conducted outside the ASVP community, particularly the ones held with the elderly during September. Through this activity, they were able to hone their communication skills because they get to assist and communicate with them.

One of the concrete values that the residents learned through this activity was the respect for the dignity of others, especially the elderly. One participant mentioned, "Through this activity, I learned the value of being a buman being and respect for the elderly."

Attendance to other gatherings and social activities such as feast days and foundation day celebrations made the residents feel that they belong to one big happy family. Comparing these celebrations with his family occasions, one participant said, "In my family, we only celebrate during birthdays. Here, there are many opportunities to celebrate together."

The children also learned to balance their time for studying, doing household chores, having some time to play games or sports, and helping one another. Thus, developing selfdiscipline, cooperation, and generosity.

5. Medical Assistance

The beneficiaries of the SETON Home were very satisfied with the medical assistance they receive from ASVP through its volunteer doctors. One recipient shared that he owes his life to the Institution. He lost his home due to a strong typhoon. He also got into an accident that almost cost him his life. Though he has been staying at ASVP for three months already, the Institution still provides his medicines, including his therapy and even his diapers.

6. Financial, Legal, and Moral Support

The endless support provided by the sisters was very much appreciated because aside from food, clothes, shelter, and hospitalization, the moral support that they give was enough motivation for them to continuously hope for a better life in the future. "Because we are refugees, we sometimes encounter many problems. So, the moral support of the organization is very much appreciated," one of the Pakistani mothers said.

The Pakistani families also encountered issues regarding the required documents that they need to accomplish to stay legally in the country. They have been required to appear in public offices a lot of times already. The sisters, especially Sr. Marilou C. Baaco, D.C., would accompany them. One of the children mentioned, "With certain issues like the documents, and if we need sometbing from public offices, Sr. Malou accompanies my mother. That's very belpful. I feel grateful."

\section{The Donors and Benefactors}

The following are some of the most exciting comments of donors/benefactors:

When asked about the best times or the significant experiences they had in partnering with Asilo, Mr. Yee spontaneously exclaimed, "They are God's blessings to us! Our business could not have existed without them."

Aside from ASVP as their company partner, Mr. Yee also mentioned that the Institution has been their spiritual partner. He always asks the sisters to pray for them, to guide them, and to shepherd them. He describes their relationship with ASVP, "Their simplicity and openness are admirable. We co-exist in a harmonious way. They have been belping us not only in our business but also spiritually. We are blessings to each other. That's our relationship through the years." 
Mr. Yee also considers the invitations from ASVP to attend special events such as anniversaries as one of the memorable experiences they had with them. He had the opportunity to meet the other members of the community, the sponsors and benefactors, and the scholars or grantees. He also appreciates the acknowledgment given to the benefactors, though for him it is not required.

Ms. Toledo, on the other hand, shared that one of the significant moments that their organization, the Rotary Club of Manila, has with ASVP is when beneficiaries give their testimonies and tell them what they have become after their time in the Institution. Sometimes the sisters tell them about their stories, how they are now gainfully employed, and that makes them happy and fulfilled. When beneficiaries meet some members of the trustees during some occasions, they would voluntarily approach them and express their gratitude. These are the reasons why their advocacy continues. "This is heart-warming. I'm also happy that they also learn to be grateful," she exclaimed.

Moreover, Alex and Dina, a couple who have been helping ASVP, said, "We are very happy. And for us, the best moment is when we see the children happy also. We are grateful that we are given this opportunity to belp and be able to share our blessings."

Alex and Dina feel happiest when they see the report cards and photos of the children because they know that they are making a difference in their lives, even without the kids knowing where the help comes from. They reiterated that they do not want their identities revealed because they don't want the kids to feel embarrassed when they meet personally. However, they are no longer sure about their anonymity during the second year because one time, they heard the children saying, "You are our parents here. You are our dad and mom!" These simple statements made the couple very happy.

Though there is no guarantee that the foreign children will be able to finish school because of some documentation issues, Dina optimistically said that the children have personally grown and learned and that the learning they get is something that will be there forever.

"It's so spontaneous!" This is what Dina remarked. "We don't know them, we did not prepare for it, and suddenly, we became sponsors. We didn't even save up for this but what's amazing is that blessings keep coming and resources never run out." The couple considers helping them as "paying it forward" because they've also gone through a difficult experience and many people helped them.

Finally, Dr. Liao considers his happiness and fulfillment to be able to share his blessings and the opportunity to be of help to others as his "bigh moment" with ASVP. He said, "I realized that you could do something good without expecting any compensation or anything in return, and at the same time you're happy with what you're doing."

Aside from sharing his profession as a dentist to the children, sisters, staff, and clients of the Institution, Dr. Liao also shares his financial blessings. He does not have anything against feeding the children, but he prefers giving cash so that it can be used for something more urgent and important.

When asked until when will he be engaged with ASVP, he exclaimed, 'By God's grace, as long as the Lord allows!" For Dr. Liao, serving the Institution is a mission that he needs to fulfill. "God is in control!" God has put me here for a purpose!" He acknowledged that there are many ways of helping but with ASVP, it is more concrete, and he knows where it is heading.

\section{The Administrators}

The influence of OD interventions is not so much on the knowledge gained but on how each member of the Administrative Council assimilates all learnings. The following themes were identified based on their accounts: 
1. Personal Self-Giving and Acceptance of Change

The administrators felt that change was difficult in the beginning especially that they also come from different ministries. One of them shared, "Introducing change is a struggle. All of us struggled. All the interventions are clear but ownership and embracing the task is a different matter. It requires personal self-giving and acceptance of the changes from all of us."

Kanter, Stein, and Jick (1992) consider that OD interventions require a strong leadership role. For them, the organization will never be ready to face any large-scale challenge without someone to lead them. Since change trickle down and directly affects a company or organization, motivating every key player and member of the company should be involved in the creation of a strong organizational structure. Additionally, leadership programs provide positive significant impacts on the overall state of the organization and its structure. The involvement of everyone in the organization should always be present, as it will be guided and continuously enhanced by a strong leader (Leonard \& Goff, 2003).

2. Common Understanding of the Responsibility of Line Managers

Before the interventions, there was a lack of clear understanding of the responsibility of the line managers. After undergoing the interventions, one of the administrators said:

Now, we already have a common understanding. That was one of the great impacts of the interventions. I'm glad they realize and own the processes. This is a great factor. That's why their sense of self-giving, a value they live as Vincentians, for the service of the poor, is understood in a deeper meaning. They give because they see that the lives of the people they are belping are improving and that the vision, mission, and values of the Institution are concretized.

3. Translation of Knowledge to Attitude and Behavior

The things that the administrators learned and experienced from all the interventions had a great impact on their attitude and behaviors. As one affirmed, "The true meaning of sharing has come to our awareness and now concretized in our actions." In a study conducted to assess the relationship of knowledge to attitude and behavior, results showed that the role of knowledge strongly affects the differences in an individual's attitude stability and other properties. When an attitude-relevant knowledge increases, it will most likely have a positive effect on the person's behavior and actions (Fabrigar, Richard, \& Steven, 2006).

4. Clear Direction and delineation of duties and responsibilities

The whole institution is now gearing towards the same and clearer direction. One administrator explained:

Based on the different interventions implemented since 2015, one thing we achieved is that ASVP now has a clearer direction. Although the process of going to that direction is a little difficult because of the culture that has evolved within ASVP, yet we can still recognize the success stories. The good thing is that at the end of the day, we realize a lot of beautiful things bappen.

Another administrator affirmed, "The revision of the organizational structure led to the re-alignment of positions. The responsibilities of each department became clearer." The ASF Department Head further confirmed:

The delineation of duties and responsibilities became clearer. There was involvement from all the members. Even the second liners can already assume the roles of other positions because these are already written in the Moments of Truth. And it led to the discovery of the potentials of every person that gave life to the Institution. There was a clarity of functions. We were made aware of new processes in the business world. We realized that we need to blend-in that's why we need all the knowledge to move forward so that we can reach out to the people who need us. 
5. Openness and Humility to Accept Change

Accepting change is a struggle because we are used to doing things out of comfort or habit. But with humility, change is easier to accept and embrace. One of the administrators shared:

Now I can say I am open to change. It's but natural that at first, a person may be besitant. Even doing the Moments of Truth is taxing because we need to monitor the employees from the moment they time-in. But at the end of the day, they are happy to know what they did and what they failed to do. So, as an administrator, I am happy to see this change, though imperfect still. What is important is our bumility to embrace the changes introduced by the OD Consultant.

6. Communication and Dialogue

Communication between and among the administrators is a big challenge in the Institution. However, because of the interventions, regular opportunities to talk and meet were provided. One said, "the impact of the interventions on the administrative council is that we always communicate. We always dialogue with each other."

Whitney (2010) says that when people work well together a kind of communion occurs, a spiritual resonance. This is further described by Briskin, Erickson, and Callanan (2009) as collective wisdom, a palpable sense of connection to each other, and larger forces, it is more than just collaboration.

Paddock (2003) cited what Fr. Chlebo said that the overriding goal that emerged in the appreciative planning process was to enhance communications at St. Christopher Parish in Rocky River, Ohio.

7. Patience and Seeing the Goodness in Others

The administrators did not only see the positive impact of the intervention towards themselves but also towards their employees. "Openness is what we need to be real servants of the Institution. I also learned patience and to see the goodness in others. Try to understand where they are coming from and where am I coming from."

As it is, serving the people also means organizing everything they need, concretizing the purpose to recreate the future as guided by the core values, reinventing structures, processes, and procedures, reskilling and developing people, and further enhancing the Vincentian culture to be able to effectively serve them.

\section{CONCLUSIONS, RECOMMENDATIONS, AND LIMITATIONS}

Organization transformation is usually a painful process because there are certain old things to be discarded and new ones to be accepted and assimilated. This is a catalyst for ASVP to attain what it envisions to be: A Haven of Hope for people living in poverty situations.

\section{Conclusions}

First, the AI process is an effective tool for planned change in terms of moving a group of people or stakeholders with multiple agendas within ASVP as an institution towards a collective view of the future. It produces a positive environment where stakeholders can transcend the pressing issues for development and improvement and celebrate the strengths of the Institution. Storytelling is a very powerful tool in creating images and building relationships with people. The focus on the positive produces an equally positive perspective among all the stakeholders involved.

Second, every stakeholder can take an active role in renewing and transforming the organization. Hence there is a practice of participative management using AI as a tool in strategic and operational planning. AI has been done to transform individuals leading to the group and organizational transformation, as follows: 
- AI involved integrated strategic change planning.

- It involved culture change - trying to help ASVP develop culture appropriate to the strategies and environment identified in the strategic planning.

- It helped ASVP to gain the capacity to alter itself fundamentally

- The process of AI itself geared the organization toward organization learning and knowledge management.

Third, AI, having been introduced and undertaken at ASVP led to the discovery of the lifegiving forces, propositions for the future, and action plans. These were translated to vision, mission, values, strategies, and goals, and specific programs and projects with their respective indicators of measurement. However, as AI has been used as a powerful tool in planning, it is not yet seen as a way of life in the Institution. It takes time for the leadership of the administration to adopt it as a way of life.

Fourth, BSC was used in translating vision and strategies into actions. The vision, mission, and values were communicated and linked to give rise to restructuring (Techno-structural intervention), systems and procedures formulation and enhancement (Techno-structural intervention), desired culture and paradigm change (Strategic intervention), human relations (Human processes intervention), and learning and development (Human resource management interventions).

Based on the research results, the following areas (as initially seen by the now Sister Servant as areas for improvement) were addressed by the OD interventions: clarification and delineation of roles and responsibilities, the flow of communication, and authority and accountability. However, there is still a transition period on the correcting of inconsistencies in the actions taken by the human resources with the policies and guidelines in the operations manual. Re-orientation on all policies and guidelines, as well as on the new performance management system and planning, monitoring, and evaluation system has to be done. The integration of the knowledge, attitude, and practice of all the institution's stakeholders, and alignment of the culture with the institution's vision, mission, and values shall also be addressed in the revisiting and operationalization/concretization of the Institution's vision, mission, and values. This will lead to the clarification of the desired behaviors of everyone in the fulfillment of the Institution's mission towards the attainment of its vision. The monitoring and evaluation part is also critical on the part of the Administration.

There are a paradox and dilemma associated with organizational transformation. There is no question that ASVP, to survive and prosper in the future, has to transform its basic structure. Alzona, Beldad, and Pick (2016) explained that ideally, the transformation of an organization is a change in culture and a change in attitude and often a change in purpose. Moreover, transformation is not something one does for an organization. It is a process that every stakeholder goes through himself/herself.

As observed, ASVP has already exhibited "good" practices in terms of the programs that it is undertaking as an institution. It has a very unique and distinct story that would contribute more to its good image and impact on its clients and the community as social welfare and development institution. The story of ASVP has just started and its destiny largely depends on all its LAMPs, more so on its management/administration. In fact, as of now, it has already achieved Level 3 DSWD accreditation in implementing residential-based programs and services for children and youth. 


\section{Recommendations}

OD interventions encompass other change initiatives. That is why it is difficult to identify their impact and effectiveness in isolation. Hence, the OD interventions should be reviewed and evaluated continually, and enhanced regularly. Likewise, evaluation of outputs should be done based on the variables and key performance indicators defined and identified in the planning stage.

ASVP has to continually implement interventions as it employs various change agents. The purpose of such interventions is to improve productivity, performance, or behaviors through a series of structured individual and team activities that focus on what employees do and how they do it. Thus, Figure 3 shows the recommended organization development framework for 20192022.

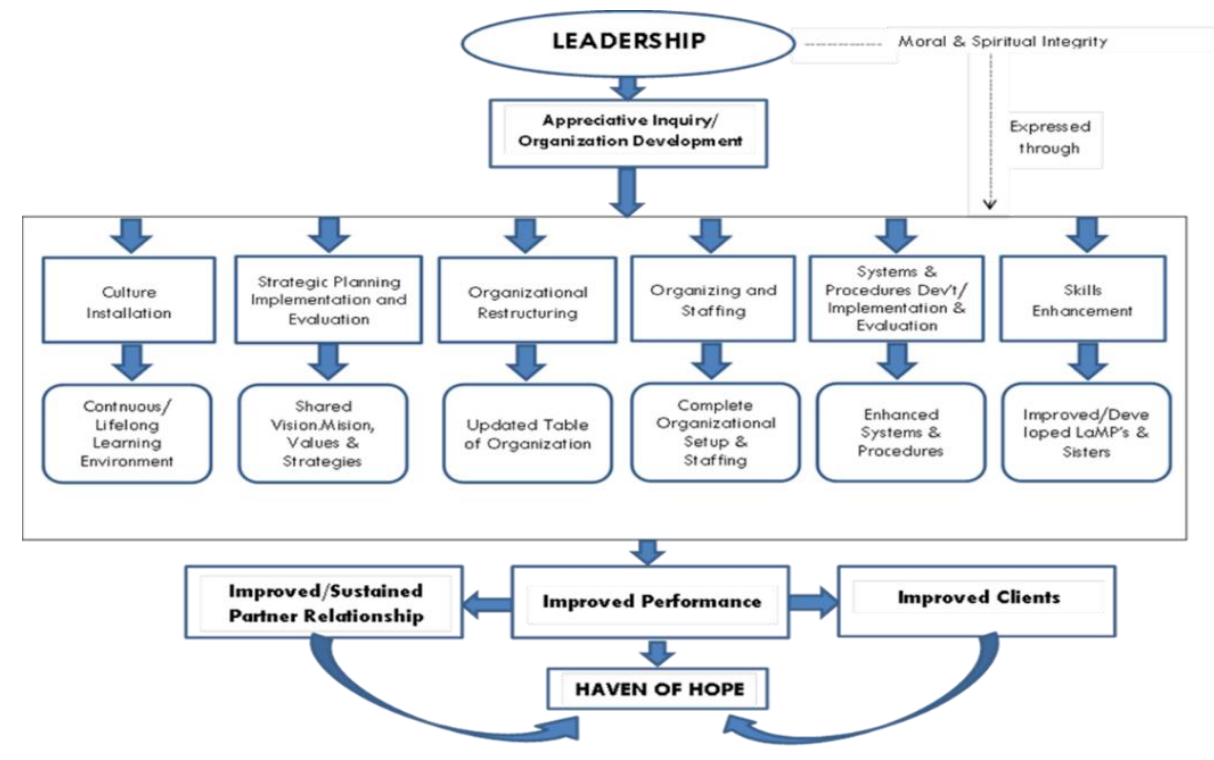

Figure 3. The Recommended Organization Development Framework for ASVP 20192022

\section{Leadership}

The LaMPs are a large fraction of ASVP's investment in providing service to its clients. Since the LaMPs can make the difference between ASVP's success and failure, administration/top management should better know how to manage and lead them toward the attainment of the Institution's goals and objectives. Therefore, visionary leaders working as change agents, developing a vision, and providing continuous and sustained support is paramount.

\section{Culture Installation}

The critical part of culture installation lies in the hands of the Administrator. With the presence and visibility of a leader, the most powerful way to connect is to tell stories to inspire the LaMPs and other stakeholders. With this, the leader would be able to hand out wisdom which listeners/LaMPs, donors and benefactors, clients, partners, and other stakeholders can use in any way they want and mold it according to their understanding, according to their needs and yet be able to find common ground between them and the administrator. This will inspire listeners to take ownership, make silent commitments to act, and be responsible for what is co-championed and generated between them and their leader.

\section{Appreciative Inquiry/Organization Development}

All ASVP Members must support what they help build. To create change, all LaMPs should have opportunities to participate actively in the decisions and achievements of ASVP. Doing 
so will help create a sense of ownership and loyalty in all employees and help them to embrace change agents.

One way of practicing participative and collaborative management is through sustaining AI as a way of life and as a tool for strategic planning, team and community building, leadership management, and action research. Encompassing all projects and activities, every project and activity can be done with AI as a basis and foundation.

\section{Strategic Planning, Monitoring, and Evaluation}

Strategic interventions are necessary to create change within ASVP and its relationship with the external environment. These interventions may include re-establishing relationships with alumni, partners, donors/benefactors, and other relevant stakeholders.

It is also important for ASVP to understand that the responsibility of achieving goals falls on all levels of the Institution, not just managerial strategies. Therefore, ASVP as a whole, the individual departments/units, and all employees must evaluate their activities against goals.

Hence, the following activities should be done:

a. Revisiting and Concretization of Vision, Mission, and Values (July 2019)

b. Strategic Planning for 2019-2022 (August/September 2019)

c. Operational Planning and Budgeting for FY 2020-2021 (October-November 2019)

In this case, ASVP shall continue using the BSC as a strategic management tool. The scorecard should be based on a series of cause-and-effect relationships. This should be derived from the strategy, including estimates of the response times and magnitudes of the linkages among the scorecard measures. In this case, ASVP can link the BSC to TQM - that is pursuing excellence in all programs, projects, and activities being done.

\section{Organizational Restructuring}

For ASVP to remain a healthy organization, leaders/managers should understand that decision making should occur where the sources of information are, which is not always toward the top of the chain of command. Moreover, the form should follow the function. That is, the problem, or task, or project should determine how human resources are organized. To be able to do this, employees in the Institution should have the right skill sets to perform their job functions. This is to avoid reassigning jobs that could not be done by employees occupying the respective position to another employee and thus avoiding putting much load on others.

Again, there must be a review of the present organizational structure, job descriptions, and qualification requirements. This must be reviewed vis-à-vis the existing manpower complement.

\section{Systems and Procedures Development, Implementation and Evaluation}

Employees want feedback on their performance, a sense of accomplishment, feelings of value and worth, and commitment to social responsibility. Employees need to become more efficient to improve their time management. And, of course, if ASVP would continue doing more work with fewer people, ASVP needs to make processes more efficient.

All managers should be able to combat the process by which employees become prisoners of their procedures. A regular development/ enhancement of policies, guidelines, processes, and procedures should be done by every department with the leadership of their heads, again with an emphasis on total quality management. 


\section{Skills Enhancement}

Workforce Learning and development has achieved heightened strategic importance to align the workforce with ASVP's goals and objectives as the Institution continues to seek ways to improve workforce retention and productivity. It is believed that when ASVP invests in its employees, employees will invest their time and talents back into the Institution. ASVP should also work toward developing the skills of employees and enhancing their sense of well-being.

\section{Total Quality Management (TQM)}

Total Quality Management must be given priority in the next three years. Having said all the things about interventions, evaluation of interventions can be done in terms of the following: implementation feedback - to know whether the intervention is being implemented or not, and evaluation feedback - to indicate whether the intervention is producing expected results.

Ultimately, the results of this study can serve as a reference to other social welfare and development institutions in their transformation activities. This study can be utilized by ASVP to further undertake OD interventions, monitor its implementation, and evaluate the process and results. But to be able to do this requires strong leadership that will make the LaMPs committed instead of compelled to change. Leadership does not pertain to the administrator alone, but it pertains to all Administrative Council members.

The results of this study though could neither be used as a definitive answer nor be used to disprove any hypothesis.

Every organization has its peculiar and unique characteristics that may be essentially different from the others. The theory used in this research may be applicable bur results may vary depending on the vision, culture, values, nature, and purpose of the organization under study.

\section{References}

Alzona, R., Beldad, M., \& Pick, J. (2016). Appreciating Organization Development. REX Bookstore, Manila, Philippines.

Balanced Scorecard Institute. (n.d.). What is a balanced scorecard? Retrieved from https://balancedscorecard.org/bsc-basics-overview/

Bertrand, B. (2002). Transformation within organizational culture: the gap between paper and reality. EJournal of Organizational Learning and Leadership, 1(1). Retrieved from http://www.leadingtoday.org/weleadinlearning/bb-oct02.htm.

Briskin, A., Erickson, S., \& Callanan, T. (2009). The power of collective wisdom: And the trap of collective folly. Berrett-Koehler Publishers, Oakland: CA.

Brown, D., Leach, M., \& Covey, J. (2008). Organization development for social change in Handbook of Organizational Development. Sage Publications: Thousand Oaks, CA.

Bushe, G. (2011). Appreciative inquiry: Theory and critique. In Boje, D., Burnes, B. and Hassard, J. (eds.) The Routledge Companion To Organizational Change, 87-103. Retrieved from http://gervasebushe.ca/AITC.pdf

Clawson, J. (2003). Leadership and Organizational Behavior. University of Virginia, Charlottesville, VA.

Clawson, J. (2008). Leading Change. Darden Business Publishing, University of Virginia, Charlottesville, USA.

Cojocaru, S. (2010). Appreciative Supervision in Social Work. New Opportunities for Changing the Social Work Practice. Revista de Cercetare si Interventie Sociala, 29, 72-91.

Company of the Daughters of Charity of St. Vincent de Paul. (2004). Constitution and Statutes.

Cooperrider, D., \& Srivastya, S. (1987). Appreciative inquiry in organizational life. Research in Organizational Change and Development, 1, 126-169. Retrieved from https://www.centerforappreciativeinquiry.net/wpcontent/uploads/2012/05/APPRECIATIVE_ INQUIRY_IN_Orgnizational_life.pdf 
Cooperrider, D., \& Godwin, L. (2012). Positive organization development: Innovation-inspired change in an economy and ecology of strengths. Retrieved from https://www.researchgate.net/figure/DModel-of-Appreciative-Inquiry_fig1_265150118

Cummings, T., \& Worley, C. (2009). Organization development \& change (9th ed.). Cengage Learning, Mason, $\mathrm{OH}$.

Fabrigar, L., Richard, P., \& Steven, S. (2006). Understanding knowledge effects on attitude-behavior consistency: The role of relevance, complexity, and amount of knowledge. Journal of Personality and Social Psychology, 90(4), 556-577. doi:10.1037/0022-3514.90.4.556.

Fox, H. (2013). The Promise of Organizational Development in Nonprofit Human Services Organizations. Organization Development Journal, $31(2):$ 72-80.

Fredrickson, B. (2001). The role of positive emotions in positive psychology: The broaden-and-build theory of positive emotions. American Psychologist, 56(3), 218-226. doi:10.1037/0003-066X.56.3.218

Georgiev, M. (2017). The role of the balanced scorecard as a tool of strategic management and control. Journal of Innovations and Sustainability, 3(2), 31-62. Retrieved from https://www.researchgate.net/publication/317872404_The_Role_of_the_Balanced_Scorecard_a s_a_Tool_of_Strategic_Management_and_Control

Gomez, M., Bracho, C., \& Hernandez, M. (2014). Appreciative inquiry, a constant in social work. Social Sciences, 3(4), 112-120. doi:10.11648/j.ss.20140304.12

Goth, M., Wu, Y., Nguyen, H., \& Johnson, A. (2019). The moment of truth: A review, synthesis, and research agenda for the customer service experience. Annual Review of Organizational Psychology and Organizational Behavior, 6(1), 89-113. doi:10.1146/annurev-orgpsych-012218-015056

Hansen, J., Jensen, A., \& Nguyen, N. (2020). The responsible learning organization: Can Senge (1990) teach organizations how to become responsible innovators? The Learning Organization, 27(1), 65-74. doi:10.1108/tlo-11-2019-0164

Hashmi, G. (2018). Appreciative mentoring as an innovative micro-practice of employee engagement for sustainability: $A$ luxury botel's entrepreneurial journey. Springer Nature Singapore Pte Ltd.

Hussein, N., Mohamad, A., Noordin, F., \& Ishak, N. (2014). Learning organization and its effect on organizational performance and organizational innovativeness: A proposed framework for Malaysian public institutions of higher education. Procedia - Social and Behavioral Sciences, 130(2014), 299-304. Retrieved from https://www.sciencedirect.com/science/article/pii/S1877042814029450.

International Federation of Social Workers. (2004) Global Definition of Social Work [ISFW General Meeting and IASSW General Assembly Proceeding]. Retrieved from https://www.ifsw.org/whatis-social-work/global-definition-of-social-work/

Isoraite, M. (2008). The balanced scorecard method: From theory to practice. Intellectual Economics, 1(3), 1828. Retrieved from https://images.template.net/wpcontent/uploads/2016/07/01132855/Process-Performance-Sample.pdf

Jones, D., \& Truell, R. (2012). The global agenda for social work and social development: A place to link together and be effective in a globalized world. International Social Work, 55(4), 454-456. doi: $10.1177 / 0020872812440587$

Kahl, L. (2020). What is convenience sampling? Wisegeek.com. Retrieved from https://www.wisegeek.com/what-is-convenience-sampling.htm

Kanter, R., Stein, B., \& Jick, T. (1992). The challenge of organizational change: How Companies Experience It and Leaders Guide It. New York and Toronto: Free Press.

Kreiviniene, B., \& Rimkus, V. (2016). Positive social work approach: The shift from "work" towards "social". Bridges/Tiltai, 73, 83-95. doi:10.15181/tbb.v73i1.1266

Leonard, H., \& Goff, M. (2003). Leadership development as an intervention for organizational transformation: A case study. Consulting Psychology Joumal: Practice and Research, 55(1), 58-67. doi:10.1037/1061-4087.55.1.58.

McLean, G. (2005). Organization Development: Principles, Processes, Performance. Berrett-Koehler Publishers, Oakland: CA.

Moore, C. (2020). What is appreciative inquiry? A brief history and real-life examples. Positive Psychology. Retrieved from https://positivepsychology.com/appreciative-inquiry/ 
Neuman, L. (2006). Social research methods: Qualitative and quantitative approaches (6 th eds.). Retrieved from https://www.pearson.com/us/higher-education/product/Neuman-Social-Research-MethodsQualitative-and-Quantitative-Approaches-6th-Edition/9780205457939.html

Neuman, L. (2011). Social science research methods: Qualitative and quantitative approaches (7th eds.). University of Wisconsin, USA.

Paddock, S. (2003). Appreciative Inquiry in the Catholic Church. Thin Book Publishing Co., USA

Raziq, A., \& Maulabakhsh, R. (2015). Impact of working environment on job satisfaction. Procedia Economics and Finance, 23(2015), 717-725. doi:10.1016/S2212-5671(15)00524-9

Reed, J. (2014). Spirituality and appreciative inquiry: Encounters with appreciative inquiry and buddhism. International Journal of Appreciative Inquiry, 16(3), 18-20. doi:10.12781/978-1-9075429-21-2-3.

Resnick, H., \& Menefee, D. (1993). A comparative analysis of organization development and social work, with suggestions for what organization development can do for social work. The Journal of Applied Behavioral Science, 29(4): 432-445. doi:10.1177/0021886393294004

Sfetcu, N. (2020). Emotions and emotional intelligence in organizations. Retrieved from https://www.researchgate.net/publication/339274827_Emotions_and_Emotional_Intelligence_i n_Organizations

Smith, D. (2017). The moment of truth: A co-creation perspective. W.P Carey School of Business. Retrieved https:// research.wpcarey.asu.edu/services-leadership/2017/01/20/the-moment-of-truth-a-cocreation-perspective/

Somerville, M., \& Farner, M. (2012). Appreciative Inquiry: A transformative approach for initiating shared leadership and organizational learning. Revista de Cercetare si Interventie Sociala [Review of Research and Social Intervention], 38(September), 7-24. Retrieved from https://scholarlycommons.pacific.edu/libraries-articles/10

Thorndike, R., \& Hagen, E. (1969). Measurement and evaluation in Psychology and education (3 ${ }^{\text {rd }}$ eds.). Educational and Psychological Measurement, 30(2), 504-506. doi:10.1177/001316447003000245

Willis, J. (2007). Foundations of qualitative research: Interpretive and critical approaches. The Social Science Journal, 44(3), 582-584. doi:10.1016/j.soscij.2007.07.007

Whitney, D. (2010). Appreciative Inquiry: creating spiritual resonance in the workplace. Joumal of Management, Spirituality, and Religion, 1, 73-88. doi:10.1080/14766080903497656 


\section{Appendix 1}

\section{FGD Questionnaire}

\section{Interview Guide for the Clients}

\section{OD Interventions Undertaken for ASVP in 2015-2018: A Developmental Study}

This study aims to achieve the following objectives:

1. Document the OD interventions undertaken by the ASVP from 2015-2018;

2. Develop a holistic understanding of all OD interventions undertaken by ASVP;

3. Document all immediate outcomes of ASVP from 2015-2018; and

4. Recommend an ASVP OD Intervention Action Plan for 2019-2021.

Questions for the FGD:

1. What are the different ASVP programs, activities, and services that you have participated in? Explain the program/activity/service.

\begin{tabular}{|c|c|}
\hline Program/Activity/Service & Nature of the Program/Activity/Service \\
\hline & \\
\hline & \\
\hline
\end{tabular}

2. What was the most significant/memorable moment/experience that you have had at Asilo? Why?

\begin{tabular}{|c|c|}
\hline Significant/Memorable Moment & Reason \\
\hline & \\
\hline & \\
\hline
\end{tabular}

3. If you have 3 wishes for ASVP, what would these be? Why?

\begin{tabular}{|c|c|}
\hline Wishes & Why \\
\hline & \\
\hline
\end{tabular}

4. If you have 3 wishes for yourself, what would these be? Why?

\begin{tabular}{|c|c|}
\hline Wishes & Why \\
\hline & \\
\hline
\end{tabular}




\section{Interview Guide for the Lay Mission Partners \\ OD Interventions Undertaken for ASVP in 2015-2018: A Developmental Study}

This study aims to achieve the following objectives:

1. Document the OD interventions undertaken by the ASVP from 2015-2018;

2. Develop a holistic understanding of all OD interventions undertaken by ASVP;

3. Document all immediate outcomes of ASVP from 2015-2018; and

4. Recommend an ASVP OD Intervention Action Plan for 2019-2021.

\section{Questions for the FGD:}

1. Self-introduction. Give me/us the best self-description of yourself. Tell me/us about your strengths. Tell me/us about your unique contribution/work as part of the ASVP.

2. Recall the OD interventions that you have had at ASVP. Which among the OD intervention activities have you been a part of? Tell me/us about your experience. Any specific topic that you can still remember? How was it done? What was its impact on you/organization?

\begin{tabular}{|c|c|c|c|c|}
\hline $\begin{array}{c}\text { OD intervention } \\
\text { activity }\end{array}$ & Topic (Content) & How (Process) & \multicolumn{2}{|c|}{ Impact/Effect } \\
\hline & & & You & ASVP \\
\hline & & & & \\
\hline
\end{tabular}

3. What was the most significant learning that you can recall from that activity? What unique role/contribution did you play in that activity that without it, the turnout of the activity could have been different?

\begin{tabular}{|c|c|}
\hline Significant Learning/s & Contribution \\
\hline & \\
\hline & \\
\hline
\end{tabular}

4. What remarkable changes have you noticed/observed in yourself and in the organization (ASVP) since you participated in these OD interventions? How do you feel about these?

\begin{tabular}{|l|c|c|c|}
\hline OD intervention & \multicolumn{2}{|c|}{ Remarkable Changes } & Feelings \\
\hline & Yourself & ASVP & \\
\hline & & & \\
\hline
\end{tabular}

5. If you have 3 wishes for ASVP, what would these be? Why?

\begin{tabular}{|c|c|}
\hline Wishes & Why \\
\hline & \\
\hline
\end{tabular}

6. How do you want to see yourself and ASVP 5 years from now?

\begin{tabular}{|c|c|}
\hline Vision of yourself 5 years from now & Vision of ASVP 5 years from now \\
\hline & \\
\hline
\end{tabular}




\section{Appendix 2}

\section{KII Questionnaire}

\section{Interview Guide for Benefactors and Donors}

This study aims to achieve the following objectives:

1. Document the OD interventions undertaken by the ASVP from 2015-2018;

2. Develop a holistic understanding of all OD interventions undertaken by ASVP;

3. Document all immediate outcomes of ASVP from 2015-2018; and

4. Recommend an ASVP OD Intervention Action Plan for 2019-2021.

\section{Questions for the FGD:}

1. Self-introduction. Give me/us the best self-description of yourself. Tell me/us about your strengths. Tell $\mathrm{me} / \mathrm{us}$ about your unique contribution/work as part of the ASVP.

2. Tell us about the nature/history of your involvement with Asilo. When and how did it start?

3. What are the Asilo activities and programs that you are involved in? What is the extent and nature of your involvement?

4. Tell us about the BEST or SIGNIFICANT experiences OR the "high moments" which you have had while partnering or collaborating with Asilo. What factors do you think made these BEST or significant?

5. If you have 3 wishes for ASVP, what would these be? Why?

\begin{tabular}{|c|c|}
\hline Wishes & Why \\
\hline & \\
\hline
\end{tabular}

6. How do you want to see your partnership with ASVP 5 years from now?

\begin{tabular}{|l|l|}
\hline Vision of yourself 5 years from now & Vision of ASVP 5 years from now \\
\hline
\end{tabular}




\section{Interview Guide for the Administrative Council}

\section{OD Interventions Undertaken for ASVP in 2015-2018: A Developmental Study}

This study aims to achieve the following objectives:

1. Document the OD interventions undertaken by the ASVP from 2015-2018;

2. Develop a holistic understanding of all OD interventions undertaken by ASVP;

3. Document all immediate outcomes of ASVP from 2015-2018; and

4. Recommend an ASVP OD Intervention Action Plan for 2019-2021.

\section{Questions for the FGD:}

1. Recall the OD interventions that you have had at ASVP. Which among the OD intervention activities have you been a part of? Tell me/us about your experience. Any specific topic that you can still remember? How was it done? What was its impact on you/organization?

\begin{tabular}{|c|c|c|c|c|}
\hline $\begin{array}{c}\text { OD intervention } \\
\text { activity }\end{array}$ & Topic (Content) & How (Process) & \multicolumn{2}{|c|}{ Impact/Effect } \\
\hline & & & You & ASVP \\
\hline & & & & \\
\hline
\end{tabular}

2. What was the most significant learning that you can recall from that activity? What unique role/contribution did you play in that activity that without it, the turnout of the activity could have been different?

\begin{tabular}{|c|c|}
\hline Significant Learning/s & Contribution \\
\hline & \\
\hline & \\
\hline
\end{tabular}

3. What remarkable changes have you noticed/observed in yourself and in the organization (ASVP) since you participated in these OD interventions? How do you feel about these?

\begin{tabular}{|l|c|c|c|}
\hline OD intervention & \multicolumn{2}{|c|}{ Remarkable Changes } & Feelings \\
\hline & Yourself & ASVP & \\
\hline & & & \\
\hline & & & \\
\hline
\end{tabular}

4. If you have 3 wishes for ASVP, what would these be? Why?

\begin{tabular}{|c|c|}
\hline Wishes & Why \\
\hline & \\
\hline
\end{tabular}

